\title{
Modern Nuclear Imaging for Paragangliomas: Beyond SPECT
}

\author{
David Taïeb*1, Hartmut Neumann*2, Domenico Rubello ${ }^{3}$, Adil Al-Nahhas ${ }^{4}$, Benjamin Guillet ${ }^{1}$, and Elif Hindié5 \\ ${ }^{1}$ Department of Nuclear Medicine, La Timone University Hospital, Aix-Marseille University, Marseille, France; ${ }^{2}$ Preventive Medicine \\ Unit, Department of Medicine, University Medical Center, Albert-Ludwigs-University, Freiburg, Germany; ${ }^{3}$ Department of Nuclear \\ Medicine, PET/CT Centre, Radiology, Medical Physics, "Santa Maria della Misericordia" Hospital, Rovigo, Italy; ${ }^{4}$ Department of \\ Nuclear Medicine, Hammersmith Hospital, London, United Kingdom; and ${ }^{5}$ Department of Nuclear Medicine, Haut-Lévêque Hospital, \\ University of Bordeaux-2, Bordeaux, France
}

\begin{abstract}
Learning Objectives: On successful completion of this activity, participants should be able to describe (1) the best nuclear imaging procedures to detect pheochromocytomas/paragangliomas according to the clinical situation (e.g., sporadic vs. hereditary; primary vs. metastatic; sympathetic vs. parasympathetic) and (2) the differences in the phenotypic information obtained by various PET tracers.

Financial Disclosure: The authors of this article have indicated no relevant relationships that could be perceived as a real or apparent conflict of interest. CME Credit: SNM is accredited by the Accreditation Council for Continuing Medical Education (ACCME) to sponsor continuing education for physicians. SNM designates each JNM continuing education article for a maximum of 1.0 AMA PRA Category 1 Credit. Physicians should claim only credit commensurate with the extent of their participation in the activity.
\end{abstract}

For CE credit, participants can access this activity through the SNM Web site (http://www.snm.org/ce_online) through February 2013.

Paragangliomas are rare neuroendocrine tumors that may arise anywhere along the paraganglial system, with a high frequency of hereditary forms or multifocal disease. Most often, paragangliomas are benign and progress slowly, but metastases may occur in about $10 \%$ of patients. In this respect, nuclear imaging in combination with anatomic imaging may be required to fully delineate the extent of the disease. PET has been increasingly used in imaging paraganglioma, paralleled by great efforts toward the development of new tracers. Recent data indicate that the choice of PET tracers should be tailored to tumor localization and to the patient's genetic status. This article provides insight into the many PET radiotracers that are currently available and others that are still only under research and guides clinicians toward appropriate use in relation to genetic carrier status. In addition, this article provides nuclear medicine physicians with the background knowledge required for understanding relationships between imaging phenotypes and molecular genetics.

Key Words: positron emission tomography; PET-CT; paraganglioma; radiopharmaceuticals; genetics

J Nucl Med 2012; 53:264-274

DOI: 10.2967/jnumed.111.098152

\section{$\mathbf{P}$} aragangliomas are tumors that develop from endocrine cells derived from pluripotent neural crest stem cells and are associated with neurons of the autonomic nervous

Received Sep. 8, 2011; revision accepted Dec. 27, 2011.

For correspondence or reprints contact: David Taïeb, Department of Nuclear Medicine, La Timone University Hospital, Aix-Marseille University, Marseille, France.

E-mail: david.taieb@ap-hm.fr

${ }^{*}$ Contributed equally to this work.

COPYRIGHT @ 2012 by the Society of Nuclear Medicine, Inc. system. They may arise anywhere along the paraganglial system and can be associated with the sympathetic nervous system or the parasympathetic nervous system. The former derive from the adrenal medulla, the organ of Zuckerkandl, or other chromaffin cells that may persist beyond embryogenesis, whereas the latter develop from endocrine cells in parasympathetic branchiomeric paraganglia (chemoreceptors), mainly located in the head and neck. Thus, paragangliomas can be distributed from the skull base to the sacrum, with a preference for certain sites: middle ear (glomus tympanicum), the dome of the internal jugular vein (glomus jugulare), between the carotid arteries (carotid body), along the vagus nerve, in the mediastinum (from the aortopulmonary body or the thoracic sympathetic chain), in the adrenal medulla, and in the abdominal paraaortic regions. Based on the classification published in 2004 by the World Health Organization, the term pheochromocytoma should be reserved solely for adrenal paraganglioma. Although catecholamine hypersecretion is almost a constant feature in pheochromocytoma and sympathetic paragangliomas, only 5\% of parasympathetic paragangliomas are norepinephrinesecreting tumors.

Paragangliomas are characterized by a high frequency of hereditary forms (overall, 25\%) with a propensity for multifocal disease (1-5). Most often, paragangliomas are benign and progress slowly, but metastases may occur in about $10 \%$ of patients.

Nuclear imaging in combination with anatomic imaging may be required to fully delineate the extent of the disease. Recent data indicate that the choice of PET tracer should be tailored to tumor localization and to the patient's genetic status. 


\section{SPECTRUM OF GENE MUTATIONS IN PARAGANGLIOMAS}

Paragangliomas are characterized by diverse anatomic locations. Some correlations between the gene involved and tumor location have been found.

Molecular genetic research has so far resulted in identification of 10 susceptibility genes for tumors of the entire paraganglial system, including succinate dehydrogenase SDHB, SDHC, SDHD, Von Hippel-Lindau disease (VHL), RET (REarranged during Transfection) in Multiple Endocrine neoplasia type 2 (MEN2), neurofibromatosis type 1 (NF1), and the very recently reported susceptibility genes SDHAF2, transmembrane protein 127 (TMEM127), SDHA, and mycassociated factor X (MAX).

Pheochromocytoma may coexist with other tumor types in MEN2A and MEN2B, VHL, and NF1. In MEN2 patients, medullary thyroid carcinomas most often $(>95 \%)$ reveal the disease. VHL is an autosomal dominant disorder, which also predisposes to renal clear cell carcinoma, pancreatic serous cystadenoma and neuroendocrine tumor, and hemangioblastoma of the eye and central nervous system. NF1 is characterized by the presence of multiple neurofibromas, café au lait spots, Lisch nodules of the iris, and other rare disorders. Extraadrenal paraganglioma may also occur in multiple neoplasia syndromes such as VHL, Carney-Stratakis dyad, and Carney triad (of unknown origin).

In this direction, fundamental work has been done by Baysal et al. in Pittsburgh, who identified the SDHD gene as the susceptibility gene of paraganglioma syndrome type 1 (paraganglioma type 1) (6). It was anticipated that other subunits could become candidates for recognition. Consequently, paraganglioma types 3 and 4 have been described as associated with germline mutations of the genes SDHC and SDHB, respectively $(7,8)$.

A study was conducted by an international consortium for finding germline mutations in 989 patients with apparently nonsyndromic, adrenal, extraadrenal retroperitoneal, and thoracic paraganglial tumors (5). Predictors for an SDHx mutation were family history for paraganglial tumors, previous adrenal or extraadrenal pheochromocytoma, multiple paragangliomas, and age $40 \mathrm{y}$ or more. The mutations were found in about two thirds in the SDHB gene, followed by mutations of the genes SDHD and VHL.

Mutations in susceptibility genes, other than SDHx, are rare in head and neck paragangliomas (HNPs) (9). The likelihood of identifying germline mutations in HNP patients was addressed by Neumann et al. in 2009 (10). Of $598 \mathrm{HNP}$ patients, $31 \%$ had SDHx germline mutations (52\% were SDHD mutations, 34\% SDHB, and 14\% SDHC). Predictors for an SDHx mutation were family history of paraganglial tumors, previous adrenal or extraadrenal pheochromocytoma, multiple HNPs, age $40 \mathrm{y}$ or more, and male sex.

Paragangliomas with an underlying SDHB mutation are associated in about $30 \%$ of the carriers with an aggressive behavior and the development of metastatic disease (11).
The susceptibility gene for paraganglioma type 2 is SDHAF2 (also called SDH5) and was identified after years of intensive research by an American-Dutch cooperation in 2009 (12). Only HNPs have been reported. So far, a single mutation is known, and potentially all patients are related (13).

The search continued until 2010, when the SDHA gene-which had been a candidate since 2000-was also recognized as a tumor suppressor gene associated with paraganglial tumors $(14,15)$.

Meanwhile, Dahia's group identified the gene TMEM127 as a susceptibility gene for paraganglial tumors, though her report suggested that only the adrenal was shown as the site of such tumors $(16,17)$. Recently, the spectrum of manifestations in patients with TMEM127 mutations has been extended also to HNPs (18). Finally, in 2011, the MAX gene was identified using exome sequencing (19). So far, only 12 patients with MAX mutations are known, and all had adrenal tumors only.

\section{CHALLENGES OF NUCLEAR IMAGING}

Pheochromocytomas and abdominal extraadrenal paraganglioma usually cause symptoms of catecholamine oversecretion. By contrast, HNPs are often nonsecreting tumors but can be revealed by symptoms of compression or infiltration of the adjacent structures. The diagnosis can be established biochemically or, in cases of typical imaging features, by using different anatomic and functional imaging modalities.

Functional imaging is probably not necessary in the preoperative work-up of patients with negative genetic testing and a small pheochromocytoma. However, since the genetic status is often not available before surgery, the possibility of multifocal or metastatic disease should be considered (or excluded) in all cases, and nuclear imaging is useful in this regard (20). If there is no family history, the need to exclude multiple lesions is particularly important in younger patients $(\leq 40 \mathrm{y})$ and patients with a larger pheochromocytoma $(>5.0 \mathrm{~cm})(21)$.

In extraadrenal paraganglioma or hereditary syndromes, as well as in identifying metastatic paraganglioma, the role of pretherapy imaging is crucial for accurately staging the disease. In this respect, nuclear imaging has a leading role. Precise identification of clinical context and genetic status of patients enables a personalized use of functional imaging studies $(22,23)$. Although the extra cost and availability of new PET tracers can prove problematic, the option of not using them could lead to inappropriate management, with an adverse effect on management that should not be underestimated. It is expected that the early detection of paraganglioma may minimize complications related to mass effect and hormonal excess, facilitate curative treatment, and potentially reduce metastatic spread.

One important but unresolved question is whether early detection of small and biochemically silent paragangliomas 
in family members would improve the prognosis of patients.

\section{LIMITATIONS OF SPECT}

${ }^{131} \mathrm{I} /{ }^{123} \mathrm{I}$-metaiodobenzylguanidine (MIBG) scintigraphy and ${ }^{111}$ In-diethylenetriaminepentaacetic acid (DTPA)pentetreotide scintigraphy are the most commonly used conventional nuclear imaging techniques. MIBG is taken up from the circulation by adrenergic/sympathomedullary tissues via norepinephrine transporter (NET) (type I uptake), whereas pentetreotide binds to somatostatin receptor (SST) 2. ${ }^{131} \mathrm{I} /{ }^{123} \mathrm{I}-\mathrm{MIBG}$ scintigraphy is the traditional imaging modality for catecholamine-secreting tumors. Scanning is usually performed after $48 \mathrm{~h}$ for ${ }^{131} \mathrm{I}$-MIBG or after $24 \mathrm{~h}$ for ${ }^{123} \mathrm{I}-\mathrm{MIBG}$. Based on studies conducted without comparison to high-resolution PET, ${ }^{131}$ I-MIBG scintigraphy has sensitivity of $77 \%-90 \%$ and specificity of $95 \%-100 \%$ in the detection of pheochromocytomas. ${ }^{123}$ I-MIBG scintigraphy has better sensitivity $(88 \%$ $96 \%$ ) than ${ }^{131}$ I-MIBG because the energy of ${ }^{123}$ I photons is better suited for detection with $\gamma$-cameras, has no $\beta$-emission, and has a shorter isotope half-life ( $13 \mathrm{~h}$ vs. $8 \mathrm{~d}$ ). Thus, there is reduced dosimetry that allows for the administration of higher activity. ${ }^{123}$ I-MIBG allows more convenient SPECT imaging, which is more sensitive than planar imaging. The 3-dimensional SPECT data can be fused with CT images for anatomic correlation, which is now quite simply obtained on hybrid SPECT/CT instruments. However, ${ }^{123} \mathrm{I}$ is more expensive than ${ }^{131} \mathrm{I}$, has to be synthesized shortly before administration, and is not commercially available in all countries. Normal adrenal medulla is visualized with ${ }^{131}$ I-MIBG in about $10 \%$ of cases and with ${ }^{123} \mathrm{I}-\mathrm{MIBG}$ in $50 \%-80 \%$ of cases, and this physiologic uptake might obscure small lesions. In the MEN2 patients, with propensity for bilateral pheochromocytoma, such physiologic uptake may be a critical problem in the initial workup of patients or during follow-up after adrenal-sparing surgery. Overall, the sensitivity of MIBG imaging is lower in extraadrenal paragangliomas, metastatic paragangliomas, and recurrences.

Scanning with ${ }^{111}$ In-DTPA-pentetreotide is usually performed at 4 and $24 \mathrm{~h}$ after tracer injection. Imaging may need to be repeated later. The sensitivity of SST scintigraphy with ${ }^{111}$ In-DTPA-pentetreotide is lower than that of ${ }^{131} \mathrm{I} /{ }^{123} \mathrm{I}$-MIBG in pheochromocytomas and sympathetic paragangliomas (24-26). The sensitivity of ${ }^{111}$ In-DTPApentetreotide is also inferior to MIBG in metastatic paragangliomas, even though ${ }^{111}$ In-DTPA-pentetreotide can provide additional information in some patients with rapidly progressing metastatic paraganglioma (24-27). However, considering parasympathetic paragangliomas, several studies have demonstrated the superiority of ${ }^{111}$ In-DTPApentetreotide scintigraphy over ${ }^{131} \mathrm{I} /{ }^{123} \mathrm{I}-\mathrm{MIBG}$, with sensitivities of $89 \%-100 \%$ and $18 \%-50 \%$, respectively (28-33). SPECT with ${ }^{111}$ In-DTPA-pentetreotide is the current scintigraphy modality of reference in HNPs. However, its sensitivity needs to be revised downward in patients with hereditary syndromes because some additional lesions can be at the millimeter stage and not detectable by conventional scintigraphy (34).

Conventional ${ }^{123}$ I-MIBG SPECT and ${ }^{111}$ In-DTPA-pentetreotide SPECT are well-established nuclear imaging modalities in the staging and restaging of paragangliomas. Also, in recent years, SPECT/CT has become more widely available and has the advantage of simultaneous acquisition of both morphologic and functional data, increasing diagnostic confidence in image interpretation and enhancing sensitivity in some cases. However, these examinations are associated with practical constraints such as long imaging times, thyroid blockage and need for withdrawal of interfering medications (for MIBG scintigraphy), and gastrointestinal tract artifacts requiring bowel cleansing in some cases. The main disadvantage is probably the still-low resolution of the SPECT image, which is prone to artifacts and attenuation, limiting the ability to detect tiny lesions. SPECT also does not provide a quantifiable estimate of tumor metabolism (tracer uptake). Thus, PET has been growing rapidly in the imaging of paragangliomas, paralleled by great efforts toward the development of new tracers.

\section{PET IMAGING AND METABOLIC PHENOTYPES}

The sensitivity and resolution of PET are superior to those of SPECT scintigraphy (the current theoretic resolution of PET on phantoms is $4-5 \mathrm{~mm}$, and in true clinical settings the resolution is close to $7-10 \mathrm{~mm}$ ). PET is also a quantitative imaging technique. Most commonly, the standardized uptake value (SUV) is used to estimate the degree of tracer concentration in a defined region. In cases of small lesions, the partial-volume phenomenon affects images both qualitatively and quantitatively, underestimating the SUV and sometimes missing such lesions. However, detection of subcentimetric lesions remains possible in cases of high tracer avidity with a favorable signal-to-noise ratio, as is frequently observed with the specific tracers used to investigate paragangliomas.

PET is a cornerstone in the evaluation of paragangliomas. The broad diversity of PET biomarkers enables assessment of different metabolic pathways that appear to be determined largely by the underlying genotypes and related tumor cell characteristics. ${ }^{18} \mathrm{~F}-\mathrm{FDG}$ is the most accessible tracer and plays an increasingly important role in paraganglioma imaging. $6-{ }^{18} \mathrm{~F}$-fluoro-L-dopa ( ${ }^{18} \mathrm{~F}$-FDOPA) is also available from different pharmaceutical suppliers. Other tracers, such as ${ }^{18} \mathrm{~F}$-fluorodopamine $\left({ }^{18} \mathrm{~F}\right.$-FDA $),{ }^{11} \mathrm{C}$-hydroxyephedrine $\left({ }^{11} \mathrm{C}\right.$-HED), and ${ }^{68} \mathrm{Ga}$-labeled peptides, are still in the evaluation stage and are used in the setting of clinical trials, though ${ }^{68} \mathrm{Ga}$-peptides are currently used in many centers for clinical purposes.

\section{Glucose Metabolism Phenotype}

${ }^{18} \mathrm{~F}-\mathrm{FDG}$ uptake reflects glucose uptake and, indirectly, energy metabolism. ${ }^{18} \mathrm{~F}-\mathrm{FDG}$ is taken up by tumor cells via glucose membrane transporters (mainly GLUT-1 and 
GLUT-3) and are phosphorylated by hexokinase into ${ }^{18} \mathrm{~F}$ FDG-6P (Fig. 1). Because increased uptake of ${ }^{18} \mathrm{~F}-\mathrm{FDG}$ is not specific to paragangliomas and because the first clinical results were disappointing $(35,36)$, its use for this indication was delayed. Yet, as explained later, most paragangliomas are avid for ${ }^{18} \mathrm{~F}$-FDG despite their relative indolence. This finding contrasts with the observation that other endocrine tumors (i.e., follicle-derived thyroid carcinoma, medullary thyroid carcinomas, and endocrine tumors of the digestive tract) generally exhibit a 2-phase metabolic profile: an initially low or absent ${ }^{18} \mathrm{~F}$-FDG uptake that increases in the later stages of the disease $(37,38)$.

\section{Catecholaminergic Phenotype}

${ }^{11} \mathrm{C}$-HED and ${ }^{18} \mathrm{~F}$-FDA illustrate the properties of uptake and storage of catecholamines (chromaffin-derived cells) and were first developed to investigate the sympathetic innervation of the myocardium. Their storage in cytoplasmic vesicles requires the expression of vesicular monamine transporters (VMAT-1 and VMAT-2) (Fig. 1). ${ }^{11} \mathrm{C}-\mathrm{HED}$ PET was first evaluated in paragangliomas by Shulkin et al. from the University of Michigan (39). ${ }^{11} \mathrm{C}-\mathrm{HED}$ is captured by tumor cells via NET (Fig. 1) and has the same reuptake and storage characteristics as norepinephrine but is resistant to the action of both catechol- $O$-methyltransferase and monoamine oxidase enzymes. ${ }^{11} \mathrm{C}-\mathrm{HED}$ has shown excellent sensitivity for paragangliomas. However, its synthesis is complex, and the short half-life of ${ }^{11} \mathrm{C}$ (20 min) requires an on-site cyclotron, a major drawback for routine clinical use.
${ }^{18} \mathrm{~F}$-FDA has been developed as an alternative to ${ }^{11} \mathrm{C}$ HED PET. Its synthesis has been standardized at the National Institutes of Health, and it is currently used as an experimental tracer at the National Institutes of Health (40). Dopamine is a catecholamine precursor. In vitro, ${ }^{18} \mathrm{~F}-$ FDA has not demonstrated any difference from dopamine concerning its membrane transport by NET. After cellular uptake, ${ }^{18} \mathrm{~F}$-FDA is stored in intracellular vesicles. NET and VMATs are strongly expressed in pheochromocytomas and paragangliomas (Fig. 1). Furthermore, dopamine can also potentially bind to specific receptors expressed in paragangliomas, in particular $\mathrm{D}_{2}$ receptors (41).

\section{Amine Precursor Uptake and Decarboxylation Phenotype}

In addition to expressing NET, paragangliomas can also decarboxylate amino acids such as dihydroxyphenylalanine. This property, common to tumors in the amine precursor uptake and decarboxylation system, depends on an enzyme that catalyzes the limiting step in the synthesis of catecholamines and of serotonin: aromatic amino acid decarboxylase. Dihydroxyphenylalanine is the precursor of all endogenous catecholamines. Dihydroxyphenylalanine is taken up through the sodium-independent large neutral amino acid transporter type 1 (LAT1). Membrane localization of this transporter requires heterodimerization with CD98, the heavy chain of 4F2 cell surface antigen (Fig. 1).

${ }^{18}$ F-FDOPA was initially developed to investigate dopaminergic neurotransmission. Hoegerle et al. were the first to demonstrate the utility of ${ }^{18}$ F-FDOPA PET to evaluate paraganglioma (42). ${ }^{18}$ F-FDOPA binds to LAT1 with high

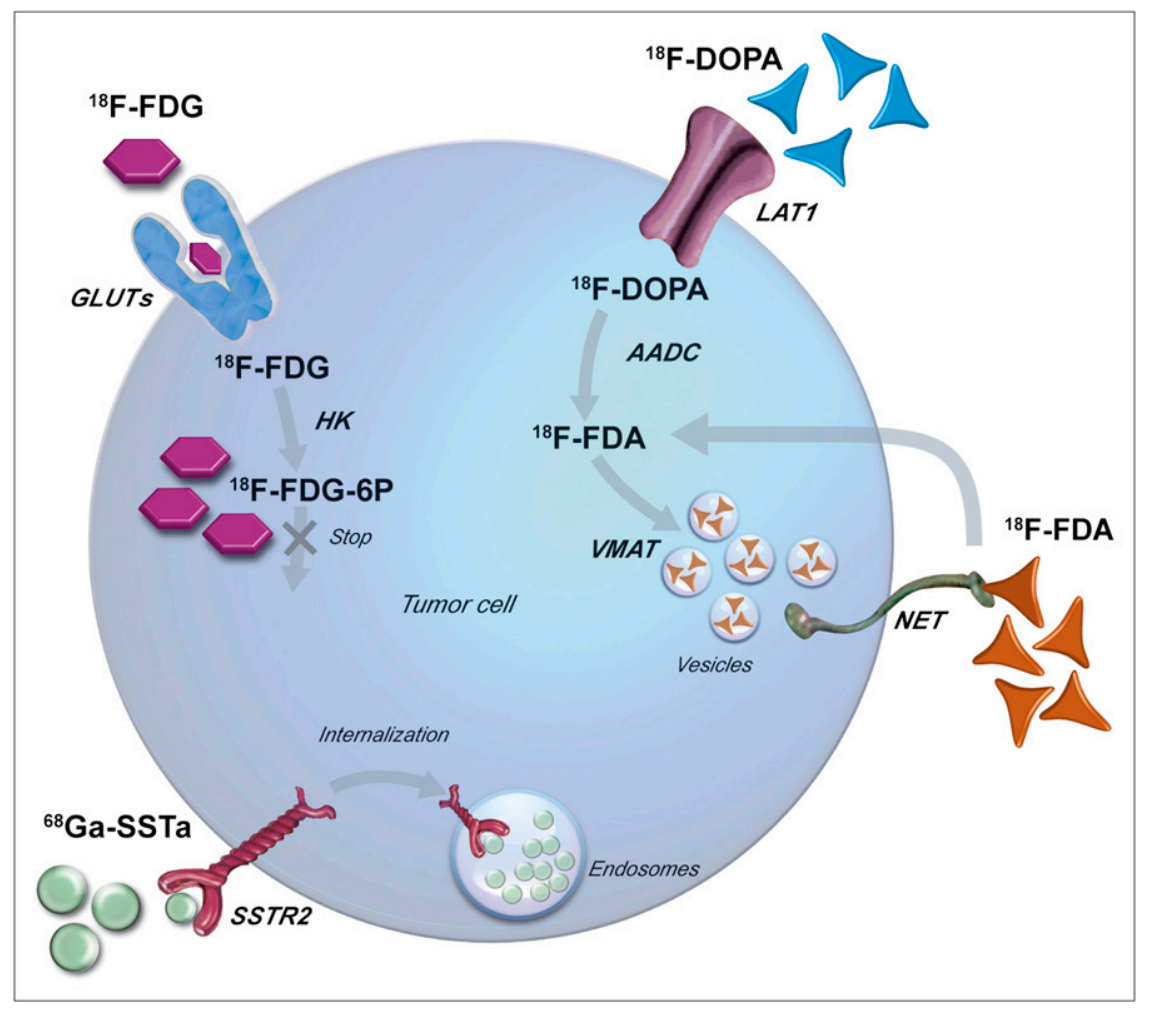

FIGURE 1. Schematic display of mechanisms of uptake and retention of some PET tracers in tumor cells of neural crest origin. LAT1 requires dimerization with CD98 for targeting to plasma membrane. $\mathrm{HK}=$ hexokinase; $\mathrm{AADC}=$ aromatic Lamino decarboxylase. 
affinity and is converted into ${ }^{18} \mathrm{~F}$-FDA by cytosolic aromatic amino acid decarboxylase. Since ${ }^{18}$ F-FDOPA is quickly converted into ${ }^{18} \mathrm{~F}$-dopamine in the proximal renal tubule and eliminated in the urine, premedication with carbidopa (an aromatic amino acid decarboxylase inhibitor) is used by some authors to improve bioavailability of the tracer (43). ${ }^{18} \mathrm{~F}$-FDOPA is available from different suppliers in the setting of the marketing authorization.

\section{SST Expression Phenotype}

Expression of SST has been demonstrated in paragangliomas by different techniques. SST2 is the most prevalent subtype in paragangliomas. SST1 is also strongly expressed in some paragangliomas, whereas other receptor subtypes are expressed there only slightly or not at all. The low expression of SST5 observed in paragangliomas constitutes a major difference from some endocrine tumors of the gastrointestinal tract. Based on experience with conventional scintigraphy using ${ }^{111}$ In-radiolabeled pentetreotide, PET using ${ }^{68} \mathrm{Ga}$-labeled somatostatin agonists has been evaluated in endocrine tumors with promising results. Tracer binding and retention depend on the density of SSTs on the cell surface and the degree of internalization of the ligandreceptor complex (Fig. 1). All radiolabeled agonists can target SST2 effectively, which is the SST most overexpressed in paragangliomas. Targeting of SSTs with PET tracers is obtained with DOTA-coupled somatostatin agonists (SSTa) labeled with ${ }^{68} \mathrm{Ga}$. Currently, 3 DOTA-coupled peptides-DOTATOC (Tyr3-octreotide), DOTATATE (Tyr3octreotate), and DOTANOC (Nal3-octreotide) - have excellent affinity for SST2 receptors (50\% inhibitory concentration: 2.5, 0.2, and $1.9 \mathrm{nM}$, respectively). DOTANOC also binds specifically to SST3, SST4, and SST5 receptors (44-46).

\section{CLINICAL RESULTS OF PET}

\section{Normal Versus Tumoral Adrenal Tracer Uptake}

The problem of normal uptake in the adrenal medulla potentially arises with all PET tracers but occurs mainly with ${ }^{11} \mathrm{C}$-HED $(47,48),{ }^{18} \mathrm{~F}$-FDA (49), and ${ }^{68} \mathrm{Ga}$-DOTAsomatostatin agonists. It has been recommended that adrenal maximal SUV be measured to differentiate normal uptake from pathologic uptake (49). However, there is some overlap, and the proposed thresholds might be difficult to apply in clinical practice.

The utility of ${ }^{18} \mathrm{~F}$-FDOPA is its low physiologic uptake in healthy adrenal glands (50). As regards ${ }^{18} \mathrm{~F}-\mathrm{FDG}$, the level of physiologic uptake in normal glands does not raise major diagnostic problems (51). Increased physiologic ${ }^{18}$ F-FDG uptake in the remaining adrenal gland may nevertheless occur after unilateral adrenalectomy for primary adrenocortical carcinoma but has not been reported for pheochromocytoma (52).

\section{Apparently Sporadic Pheochromocytomas}

There is no clear advantage of PET tracers over ${ }^{123} \mathrm{I}-$ MIBG SPECT in these clinical situations (53). ${ }^{123}$ I-MIBG scintigraphy is sufficient to confirm the diagnosis of appar- ently sporadic pheochromocytoma even in rare cases of nonhypersecreting pheochromocytoma. No correlation exists between test sensitivity and secretory levels of tumors. With its whole-body screening, ${ }^{123}$ I-MIBG can rule out extraadrenal disease and guide subsequent CT and MRI investigations. Its negativity should lead to consideration of interference but can also be due to low expression of VMAT-1 (54). If MIBG is negative, and diagnostic presumption of pheochromocytoma is high, any of the specific PET tracers discussed earlier $\left({ }^{18} \mathrm{~F}\right.$-FDOPA $(42,50,54-59),{ }^{18} \mathrm{~F}-\mathrm{FDA}$ $(40,60)$, or $\left.{ }^{11} \mathrm{C}-\mathrm{HED}(39,47,61)\right)$ can be attempted, with a sensitivity approaching $100 \%$ with modern PET/CT cameras. ${ }^{18} \mathrm{~F}$-FDOPA PET and ${ }^{18} \mathrm{~F}$-FDG PET can be performed

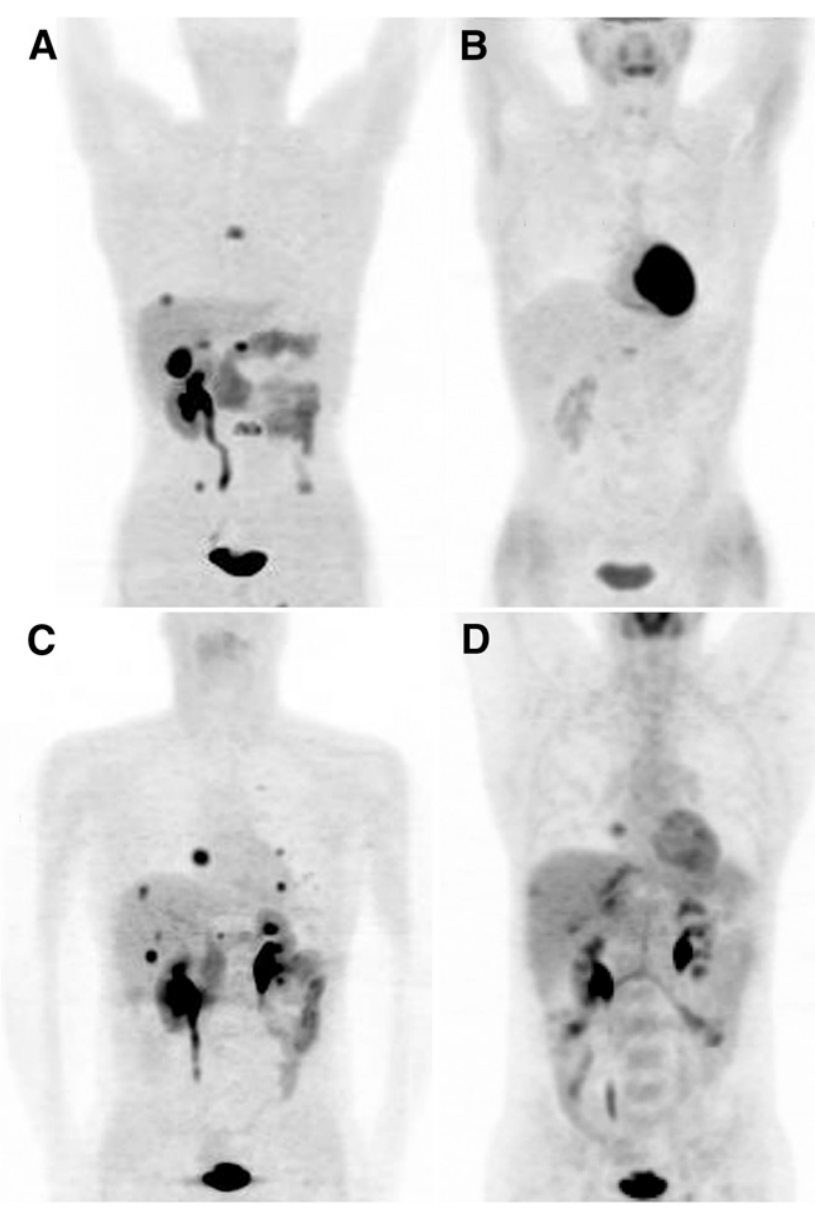

FIGURE 2. Comparison between maximal-intensity-projection ${ }^{18} \mathrm{~F}-\mathrm{FDOPA}$ and ${ }^{18} \mathrm{~F}$-FDG PET images in restaging of 2 patients with metastatic paraganglioma without SDHB mutation. (A and B) A 34-y-old man with persistent biochemical abnormalities after resectioning of multiple abdominal paragangliomas. Postoperative ${ }^{18}$ F-FDOPA PET found 2 liver metastases and thoracic and lumbar spine metastases (T6, T12, and L3; maximal SUV, 9.9), as well as osteolytic lesion of right iliac bone. Physiologic uptake is seen in kidneys, pancreas, gallbladder, and digestive tract (via bile elimination) (A). ${ }^{18} \mathrm{~F}-\mathrm{FDG}$ PET depicted only 1 metastasis (T12; maximal SUV, 2.1) (B). (C and D) A 43-y-old man with biochemical persistence after resection of large pheochromocytoma and liver metastases. Postoperative ${ }^{18} \mathrm{~F}$-FDOPA PET shows multiple liver and lung metastases (C). ${ }^{18}$ F-FDG PET underestimated number of foci; visible lesions have lower SUVs (D) 
without the need to withdraw drugs that interfere with MIBG. ${ }^{18}$ F-FDG PET is a highly sensitive modality in paragangliomas, even in cases of pheochromocytoma with low proliferative index and no mitosis. In the case of a high adrenal ${ }^{18}$ F-FDG uptake (tumor-to-liver maximal SUV ratio > 2), 4 main potential differential diagnoses should be considered: pheochromocytoma, malignant adrenal cortex tumor, primary lymphoma, and metastasis. Some features that may orientate toward pheochromocytoma are solitary lesion without vena cava involvement, decreased uptake in the central area of the tumor evidencing cystic or hemorrhagic alterations, and calcifications visible on the $\mathrm{CT}$ scan. Increased ${ }^{18} \mathrm{~F}$-FDG uptake in brown adipose tissue, due to stimulation by circulating norepinephrine, should not be confused with extraadrenal lesions; such uptake can be visualized in about $20 \%$ of patients (62).

\section{MEN2-Related Pheochromocytomas}

A special advantage of ${ }^{18}$ F-FDOPA PET over MIBG and other specific PET tracers is the lack of significant uptake in normal adrenal glands. This is particularly important in MEN2 patients for differentiating normal or hyperplastic adrenal glands from those that are tumoral. Luster et al. made a retrospective evaluation of 25 patients (including 12 with MEN2) with ${ }^{18} \mathrm{~F}$-FDOPA PET/CT (50). Overall sensitivity and specificity in detecting pheochromocytoma were $100 \%$ and $89 \%$. A combination of ${ }^{18}$ F-FDOPA PET/ $\mathrm{CT}$ and CT/MRI was found to be the optimal imaging strategy in another study (56). ${ }^{18}$ F-FDOPA PET has also been used to identify metastases from medullary thyroid carcinomas in MEN2 patients (50).

\section{Extraadrenal Retroperitoneal Paragangliomas}

In the case of a retroperitonal extraadrenal nonrenal mass, imaging should differentiate a paraganglioma from a neurogenic tumor, lymph node disease, or a mesenchymal tumor. Despite the high performance of conventional imaging, the diagnosis may remain uncertain. A biopsy is not always contributive and can carry risks. Therefore, the specificity of functional imaging provides an important contribution. Once the diagnosis of paraganglioma has been established, multiplicity of extraadrenal localizations should be considered.

MIBG is clearly superior to SST scintigraphy (24) in abdominal paraganglioma but may be suboptimal in cases of small lesions or those with special phenotypic aspects, such as VHL-related paragangliomas $(42,63)$. Studies that have included a high number of extraadrenal, multiple, or hereditary paragangliomas found reduced sensitivity for MIBG $(52 \%-75 \%)(24,53,56,60)$. Furthermore, MIBG may miss additional HNPs in hereditary syndromes. ${ }^{18} \mathrm{~F}-$ FDOPA PET was found to be more sensitive than MIBG scintigraphy in the staging and restaging of paragangliomas (42,50,54-59). In some studies, ${ }^{18}$ F-FDOPA PET significantly detected more lesions than CT/MRI. Reported sensitivities range from $81 \%$ to $100 \%$. However, ${ }^{18} \mathrm{~F}-\mathrm{FDOPA}$ PET should not be considered similar to MIBG scanning with higher sensitivity but is rather a new specific radiotracer with its own advantages and limitations. The main limitation relates to patients with SDHx mutations. In a prospective study by Fottner et al., all sympathetic paragangliomas associated with SDH mutations were positive with ${ }^{123}$ I-MIBG, whereas 2 extraadrenal paragangliomas were not detected with ${ }^{18} \mathrm{~F}$-FDOPA PET despite the centimeter size of the lesions (54). This possibility of missing certain retroperitoneal tumors has also been noted in 3 other studies $(34,53,56) .{ }^{18} \mathrm{~F}-\mathrm{FDA}$ PET is highly sensitive but may also miss some tumors $(24,60)$.

Taïeb et al. showed that ${ }^{18} \mathrm{~F}-\mathrm{FDG}$ PET positivity was not indicative of malignancy or histologic dedifferentiation in paraganglioma but rather was related to genetic status (64). In that study, SDHx and VHL-related tumors were notable in being the most ${ }^{18} \mathrm{~F}$-FDG-avid tumors. ${ }^{18} \mathrm{~F}-\mathrm{FDG}$ PET appears especially sensitive in detecting sympathetic extraadrenal paragangliomas, probably as a result of the higher prevalence of SDHB mutations in this setting.

The new PET tracers targeting SST receptors are now under evaluation in paragangliomas, and published data are
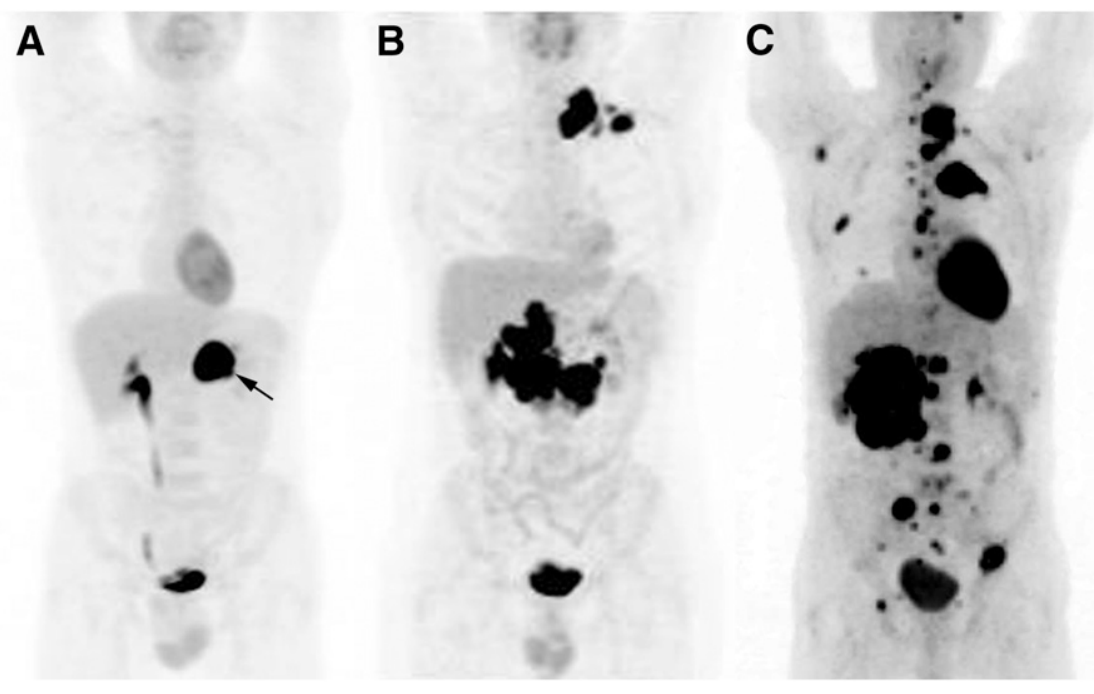

FIGURE 3. Maximal-intensity-projection ${ }^{18}$ F-FDG PET images of SDHB-related paraganglioma. (A) A 38-y-old man presenting with hypertensive crises. ${ }^{18} \mathrm{~F}-\mathrm{FDG}$ PET depicted left adrenal tumor with marked avidity (maximal SUV, 49) and no extraadrenal foci. Pathologic examination found a 33-mm pheochromocytoma without unfavorable histologic features (PHEO of Adrenal Scaled Score [PASS] $=0$, Ki-67 $<1 \%$ ). (B) A 41-y-old man with multiple abdominal paragangliomas and left metastatic supraclavicular lymph nodes. (C) A 36-y-old man with large pheochromocytoma and extensive bone metastases (spine, ribs, skull base, and hip). 
limited to case reports (65-69) and small series (70). ${ }^{68} \mathrm{Ga}$ DOTATOC and ${ }^{68} \mathrm{Ga}$-DOTATATE PET/CT were found to be superior to ${ }^{123}$ I-MIBG SPECT in some cases of aggressive paraganglioma, probably associated with a certain level of functional dedifferentiation.

\section{Metastatic Paragangliomas/Pheochromocytomas}

Imaging work-up might entail the use of more than 1 tracer. MIBG scintigraphy has been compared with ${ }^{11} \mathrm{C}$-HED $(39,48,61,71),{ }^{18} \mathrm{~F}-\mathrm{FDA}(24,60,72),{ }^{18} \mathrm{~F}-\mathrm{FDOPA}(54,56,57,73)$, and ${ }^{68} \mathrm{Ga}$-DOTA-TOC (74) and has been considered inferior to these PET tracers in most studies. The sensitivity of MIBG scintigraphy in terms of detected lesions is about $65 \%$. Thus, ${ }^{123}$ I-MIBG SPECT may lead to significant underestimation of the disease, with potential inappropriate management in apparently oligometastatic disease.

The presence of SDHB mutation markedly impacts on the choice of tracers $(53,75)$. In a prospective study by Timmers et al. (53), 28 patients had metastatic paragangliomas: 13 pheochromocytomas (3 SDHB, 1 SDHD, 1 VHL, 1 MEN2, and 7 sporadic) and 15 extraadrenal paragangliomas (12 SDHB, 1 SDHD, and 2 sporadic). These patients were imaged with different tracers. In reference to CT/MRI, overall sensitivities for ${ }^{123} \mathrm{I}$-MIBG SPECT, ${ }^{18} \mathrm{~F}$-FDG PET/CT, ${ }^{18} \mathrm{~F}-$ FDOPA PET, and ${ }^{18} \mathrm{~F}-\mathrm{FDA}$ PET/CT were, respectively, $57 \%, 74 \%, 45 \%$, and $76 \%$. On per-patient analysis, ${ }^{18} \mathrm{~F}-$ FDG PET was more frequently contributive in SDHB-positive patients, whereas ${ }^{18} \mathrm{~F}-\mathrm{FDOPA}$ PET was more frequently contributive in SDHB-negative patients. The percentage of sites detected was $57 \%$ with ${ }^{123}$ I-MIBG (57\% for SDHB-positive vs. 59\% SDHB-negative, not statistically significant), $74 \%$ for ${ }^{18} \mathrm{~F}-\mathrm{FDG}$ PET (83\% SDHB-positive vs. $62 \%$ SDHB-negative, $P<0.001$ ), $45 \%$ for ${ }^{18} \mathrm{~F}$-FDOPA PET (20\% SDHB-positive vs. 93\% SDHB-negative, $P<0.001$ ), and $76 \%$ for ${ }^{18} \mathrm{~F}-\mathrm{FDA}$ PET (82\% SDHB-positive vs. 93\% SDHB-negative, $P=$ 0.037). This study demonstrated the phenotypic heterogeneity of tumors in imaging studies and the need to combine functional imaging modalities. The main limitation of the study is that ${ }^{18} \mathrm{~F}-\mathrm{FDOPA}$, in contrast to the other tracers, has been evaluated using PET alone and not with a modern hybrid PET/CT camera, which might have decreased the value of the technique. To date, ${ }^{18} \mathrm{~F}$-FDOPA PET may be the imaging modality of choice in the absence of SDHB mutation or when genetic status is unknown (Fig. 2). ${ }^{18} \mathrm{~F}-$ FDG PET is considered the imaging modality of reference for SDHB-positive paraganglioma cases (Fig. 3; Table 1). When more widely available, ${ }^{18} \mathrm{~F}$-FDA PET will possibly be used as a first-line diagnostic imaging modality in patients with a metastatic pheochromocytoma, whatever their genetic status $(53,75,76)$. It might be too early to abandon ${ }^{123}$ I-MIBG scintigraphy, as it may offer additional information in some patients. Furthermore, ${ }^{123}$ I-MIBG scintigraphy remains an important modality to determine whether a patient is eligible for treatment with ${ }^{131}$ I-MIBG. Bone scintigraphy is also useful in SDHB-positive patients (75).

Data with ${ }^{68} \mathrm{Ga}$-labeled agonists are still limited. ${ }^{68} \mathrm{Ga}$ PET was found to be sensitive in the detection of rapidly progressing metastatic paraganglioma (Fig. 4) $(65,67,74,77)$. ${ }^{68} \mathrm{Ga}$-DOTA-SSTa should also give valuable information on tumor cell receptor status for the planning of peptide receptor radionuclide therapy (78).

\section{HNPs}

HNPs raise the problem of locoregional extension and multifocality. Metastatic forms are rare.

The results of PET in HNPs have rarely been addressed in isolation $(34,53,54,56,65,66,68,79-81)$. Hoegerle et al. have compared ${ }^{18}$ F-FDOPA PET/CT and MRI in 10 patients (79). All paragangliomas were visualized with ${ }^{18} \mathrm{~F}$ FDOPA PET, whereas 1 tiny lesion remained occult on MRI even after correlation with PET results. This study demonstrates that HNPs are highly avid for ${ }^{18} \mathrm{~F}-\mathrm{FDOPA}$ and that favorable signal-to-noise uptake ratios enable the detection of subcentimetric tumors.

These results are in line with those obtained by Charrier et al., who found a sensitivity of $97 \%$ for ${ }^{18}$ F-FDOPA PET/ CT versus $67 \%$ for SST scintigraphy (34). This lower sensitivity of SST scintigraphy probably is related to the limited resolution of SPECT. King et al. also reported results widely in favor of ${ }^{18} \mathrm{~F}$-FDOPA PET/CT in the localization of SDHx-related HNPs (sensitivity, 100\%), followed by

TABLE 1

Clinical Features and Suggestions for Imaging Work-up in Paraganglioma Syndromes

\begin{tabular}{|c|c|c|c|c|c|c|c|}
\hline Gene & $\begin{array}{c}\text { Paraganglioma } \\
\text { syndrome }\end{array}$ & HNP & $\begin{array}{l}\text { Thoracic or } \\
\text { retroperitoneal } \\
\text { paraganglioma }\end{array}$ & $\begin{array}{l}\text { Malignancy } \\
\text { risk }\end{array}$ & $\begin{array}{c}\text { First-line PET } \\
\text { modality }\end{array}$ & Second-line tracers & $\begin{array}{l}\text { Experimental PET } \\
\text { tracers of interest }\end{array}$ \\
\hline SDHB & Type 4 & + & ++ & $\sim 30 \%$ & ${ }^{18} \mathrm{~F}-\mathrm{FDG}$ & ${ }^{18} \mathrm{~F}-\mathrm{FDOPA}$ & ${ }^{18} \mathrm{~F}-\mathrm{FDA}$ \\
\hline $\mathrm{SDHC}$ & Type 3 & ++ & + (rare) & - & ${ }^{18} \mathrm{~F}-F D O P A$ & - & ${ }^{68} \mathrm{Ga}-\mathrm{SSTa}$ \\
\hline SDHD & Type $1^{*}$ & ++ & + & $<5 \%$ & ${ }^{18} \mathrm{~F}-\mathrm{FDOPA}$ & ${ }^{18} \mathrm{~F}-\mathrm{FDG},{ }^{123} \mathrm{I}-\mathrm{MIBG}$ & ${ }^{68} \mathrm{Ga}-\mathrm{SSTa}$ \\
\hline $\begin{array}{l}\text { SDHAF2 } \\
(\mathrm{SDH} 5)\end{array}$ & Type 2 & ++ & - & - & ${ }^{18}$ F-FDOPA & - & ${ }^{68} \mathrm{Ga}$ SSTa \\
\hline
\end{tabular}

*SDHD mutation is characterized by maternal imprinting; i.e., disease occurs only when mutation is inherited from father.

$-=$ never reported; $++=$ most frequent clinical manifestation. 
A
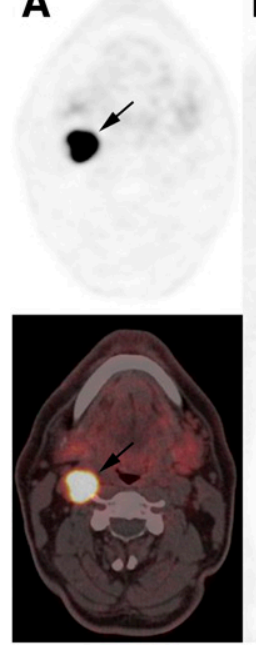

B

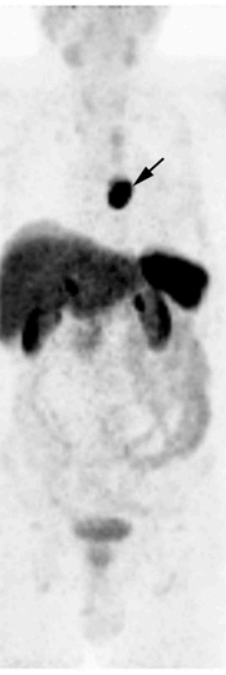

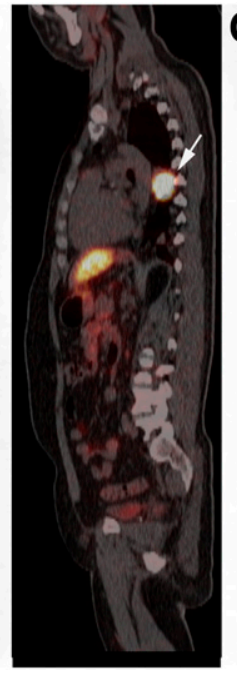

CT/MRI (81\%), ${ }^{18}$ F-FDG PET (77\%), SST scintigraphy (64\%), and ${ }^{18}$ F-FDA PET (46\%) (80).

Taken together, these studies show that ${ }^{18} \mathrm{~F}$-FDOPA PET/ CT appears to be an excellent first-line imaging tool in HNPs (Fig. 5; Table 1). ${ }^{18}$ F-FDOPA PET might miss extraadrenal retroperitoneal paraganglioma, which can potentially coexist with HNPs $(34,53,54,56)$. This leading position for ${ }^{18} \mathrm{~F}-\mathrm{FDOPA}$ PET/CT may of course further evolve if a future head-to-head comparison of ${ }^{18} \mathrm{~F}$-FDOPA PET and ${ }^{68} \mathrm{Ga}-\mathrm{SST}$ Ta PET is achieved. Preliminary results

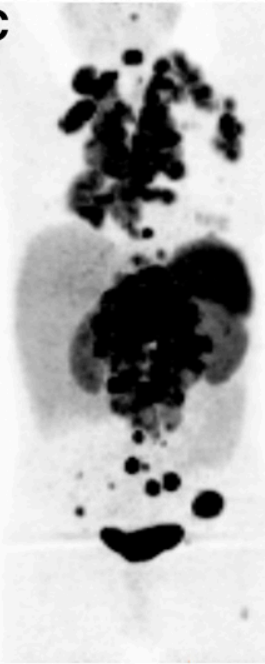

FIGURE 4. ${ }^{68} \mathrm{Ga}$-DOTATATE findings in 3 different paraganglioma patients. (A) Right carotid glomus paraganglioma (top: axial PET image; bottom: axial PET/CT fusion image). (B) Thoracic sympathetic paraganglioma (left: maximal-intensity-projection image; right: sagittal PET/CT fusion image). (C) Metastatic paraganglioma with multiple lymph nodes and metastases in lungs and bones (maximal-intensity-projection image).

for ${ }^{68} \mathrm{Ga}$-labeled DOTA peptides are encouraging (Fig. 4) $(65,66,68)$.

\section{GENOTYPE-IMAGE PHENOTYPE}

Despite the rapid and important progress achieved since the discovery of the first SDHD gene mutation a decade ago, the tumorigenesis pathways remain to be determined. Many of the predominant mutations observed in paraganglioma also control tumor cell metabolism (82-84). There is, for example, growing evidence that suggests a link
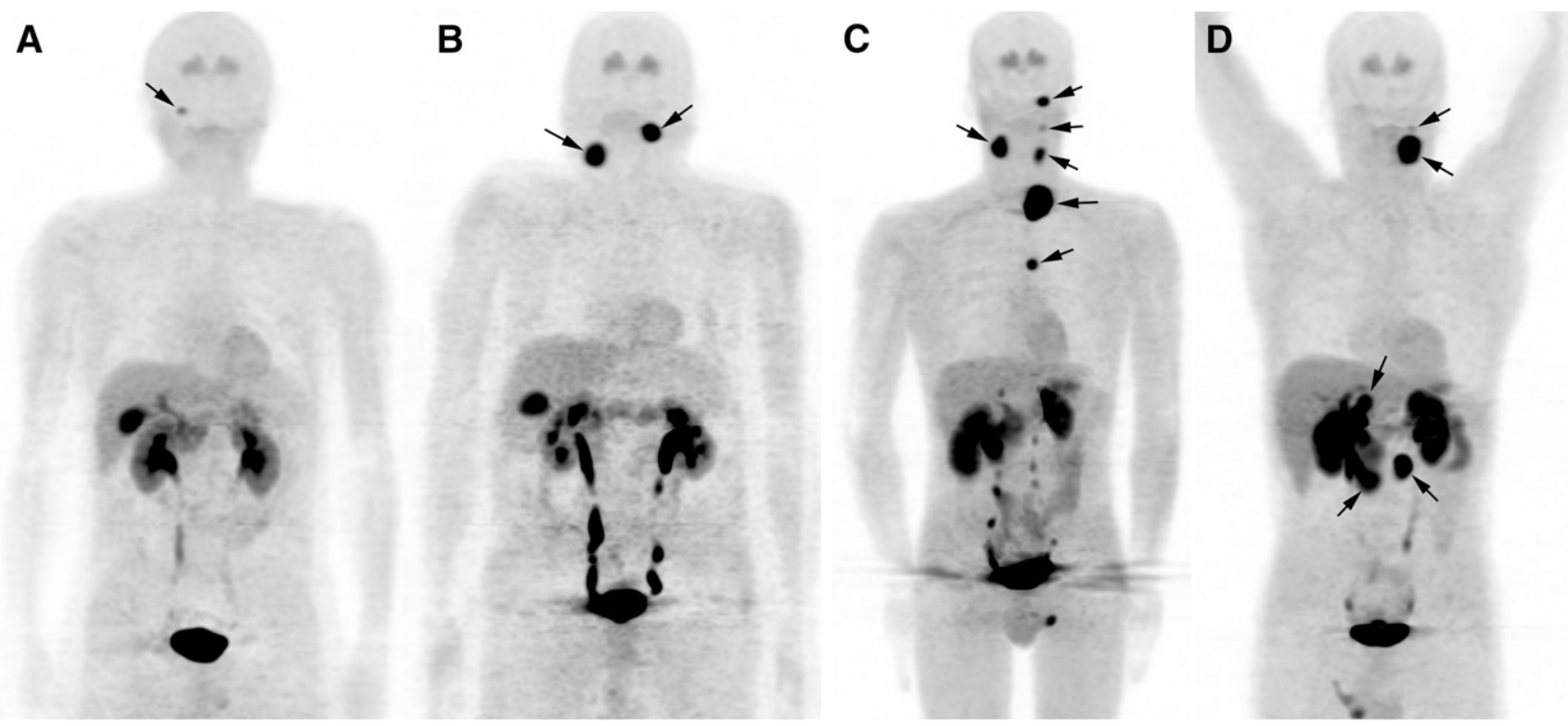

FIGURE 5. Maximal-intensity-projection ${ }^{18}$ F-FDOPA PET images of SDHx-related HNPs. (A) SDHB: A 57-y-old man who previously underwent surgery for left large carotid glomus paraganglioma associated with metastatic lymph nodes. Follow-up ${ }^{18} \mathrm{~F}-\mathrm{FDOPA}$ PET found tiny right jugular paraganglioma. ${ }^{18} \mathrm{~F}-\mathrm{FDG}$ PET was also positive. (B) SDHC: A 71-y-old man with bilateral incidentally discovered neck paragangliomas. (C) SDHD: A 47-y-old man with 6 asymptomatic parasympathetic ${ }^{18} \mathrm{~F}-\mathrm{FDOPA}$-avid paragangliomas. Two abdominal paragangliomas were missed by ${ }^{18} \mathrm{~F}-\mathrm{FDOPA}$ PET. (D) SDHD: A 39-y-old man admitted to hospital for cardiogenic shock after use of $\beta$-blocker eye drops. Imaging work-up found 2 parasympathetic paragangliomas and 6 abdominal paragangliomas. ${ }^{18} \mathrm{~F}-\mathrm{FDOPA} P E T$ identified 2 HNPs and 3 abdominal paragangliomas (arrows) but failed to identify 3 additional abdominal tumoral sites that were identified by ${ }^{18} \mathrm{~F}-\mathrm{FDG}$ PET. 
between increased ${ }^{18} \mathrm{~F}$-FDG uptake in some of the genetic mutations and activation of hypoxia signaling in tumor cells.

SDHB-mutated paragangliomas are notable in being the most ${ }^{18} \mathrm{~F}-\mathrm{FDG}$-avid tumors (64). It has been suggested that SDH and VHL-mutated tumors may have a genetically driven Warburg effect (aerobic glycolysis) (82).

In normoxia, HIF- $\alpha$ isoforms are rapidly ubiquitinylated and targeted for proteasomal degradation. The oxygensensitive signal is generated by prolyl hydroxylases that catalyze hydroxylation of HIF- $\alpha$ isoforms. Prolyl hydroxylation targets the proteins for proteasomal degradation by promoting their interaction with VHL, a component of an E3 multiprotein ubiquitin-ligase complex.

Under hypoxic conditions, prolyl hydroxylase activity decreases, prolyl hydroxylation rate slows, and proteasomal degradation rate of HIF slows, leading to stabilization of HIF- $\alpha$ isoforms and activation of genes involved in response to hypoxia. Hypoxia-induced changes in gene expression extend to several hundred transcripts, including glucose transporters, glycolytic enzymes, angiogenic factors, and erythropoietin.

SDH or VHL inactivation induces a hypoxic response in the presence of oxygen, called a pseudohypoxia state. VHL mutations may disrupt VHL-HIF interaction, leading to HIF accumulation even in the presence of oxygen. SDH inactivation, on the other hand, may impair HIF hydroxylation through increased production of succinate or reactive oxygen species (85-88). As a result, glucose uptake is increased, which can be visualized with ${ }^{18}$ F-FDG PET. Consistent with this idea, HIF- $1 \alpha$ and its downstream targets were found to be upregulated in SDHx and VHL-related tumors (89). Transcriptional profiling studies also revealed pseudohypoxic signatures in SDHx/VHL tumors that can differentiate them from RET/NF1 cases that usually have lower ${ }^{18}$ F-FDG avidity (90-92). However, even if both VHL and SDHB/D inactivations may disrupt the HIFdependent pathway, the transcriptional targets that mediate the changes may well be different. It has been found that HIF- $1 \alpha$ target genes were activated predominantly in the VHL pheochromocytomas (90-92). Taken together, these results suggest that inactivation of VHL and SDHx genes can upregulate specific HIF downstream targets and promote tumor growth, angiogenesis, metastasis, as well as ${ }^{18} \mathrm{~F}-\mathrm{FDG}$ uptake (93). However, further investigation is required to understand the sequence of events involved for a specific mutation. In the meantime, it is important to recognize that other potential key signaling pathways may regulate ${ }^{18} \mathrm{~F}-\mathrm{FDG}$ uptake and require further basic research.

Mutations in susceptibility genes also influence secretory profiles and imaging phenotypes of paraganglioma. These sets of genes are possibly essential in the control of key proteins involved in the catecholamine secretory pathway. It is notable that SDHB tumors may weakly concentrate ${ }^{18} \mathrm{~F}-\mathrm{FDOPA} .{ }^{18} \mathrm{~F}-\mathrm{FDOPA}$ PET may miss abdominal paragangliomas in patients with SDHx mutations $(34,54)$, and false-negative MIBG findings have also been reported in
VHL tumors. The relationship between determinants of cellular uptake, synthesis or secretion machinery, and germline mutations requires further evaluation.

\section{CONCLUSION}

These new findings open a range of possible insights into the association of genotype and image phenotype that could guide clinicians in better tailoring paraganglioma-imaging modalities.

\section{ACKNOWLEDGMENTS}

We thank Dr. Henri Timmers for his helpful comments and thoughtful suggestions.

\section{REFERENCES}

1. Karasek D, Frysak Z, Pacak K. Genetic testing for pheochromocytoma. Curr Hypertens Rep. 2010;12:456-464.

2. Mannelli M, Castellano M, Schiavi F, et al. Clinically guided genetic screening in a large cohort of Italian patients with pheochromocytomas and/or functional or nonfunctional paragangliomas. J Clin Endocrinol Metab. 2009;94:1541-1547.

3. Amar L, Bertherat J, Baudin E, et al. Genetic testing in pheochromocytoma or functional paraganglioma. J Clin Oncol. 2005;23:8812-8818.

4. Cascón A, Pita G, Burnichon N, et al. Genetics of pheochromocytoma and paraganglioma in Spanish patients. J Clin Endocrinol Metab. 2009;94:17011705 .

5. Erlic Z, Rybicki L, Peczkowska M, et al. Clinical predictors and algorithm for the genetic diagnosis of pheochromocytoma patients. Clin Cancer Res. 2009;15: 6378-6385.

6. Baysal BE, Ferrell RE, Willett-Brozick JE, et al. Mutations in SDHD, a mitochondrial complex II gene, in hereditary paraganglioma. Science. 2000;287:848851 .

7. Astuti D, Latif F, Dallol A, et al. Gene mutations in the succinate dehydrogenase subunit SDHB cause susceptibility to familial pheochromocytoma and to familial paraganglioma. Am J Hum Genet. 2001;69:49-54.

8. Niemann S, Muller U. Mutations in SDHC cause autosomal dominant paraganglioma, type 3. Nat Genet. 2000;26:268-270.

9. Boedeker CC, Erlic Z, Richard S, et al. Head and neck paragangliomas in von Hippel-Lindau disease and multiple endocrine neoplasia type 2. J Clin Endocrinol Metab. 2009;94:1938-1944.

10. Neumann HP, Erlic Z, Boedeker CC, et al. Clinical predictors for germline mutations in head and neck paraganglioma patients: cost reduction strategy in genetic diagnostic process as fall-out. Cancer Res. 2009;69:3650-3656.

11. Gimenez-Roqueplo AP, Favier J, Rustin P, et al. Mutations in the SDHB gene are associated with extra-adrenal and/or malignant phaeochromocytomas. Cancer Res. 2003;63:5615-5621.

12. Hao HX, Khalimonchuk O, Schraders M, et al. SDH5, a gene required for flavination of succinate dehydrogenase, is mutated in paraganglioma. Science. 2009;325:1139-1142.

13. Bayley JP, Kunst HP, Cascon A, et al. SDHAF2 mutations in familial and sporadic paraganglioma and phaeochromocytoma. Lancet Oncol. 2010;11:366-372.

14. Burnichon N, Briere JJ, Libe R, et al. SDHA is a tumor suppressor gene causing paraganglioma. Hum Mol Genet. 2010;19:3011-3020.

15. Korpershoek E, Favier J, Gaal J, et al. SDHA immunohistochemistry detects germline SDHA gene mutations in apparently sporadic paragangliomas and pheochromocytomas. J Clin Endocrinol Metab. 2011;96:E1472-E1476.

16. Qin Y, Yao L, King EE, et al. Germline mutations in TMEM127 confer susceptibility to pheochromocytoma. Nat Genet. 2010;42:229-233.

17. Yao L, Schiavi F, Cascon A, et al. Spectrum and prevalence of FP/TMEM127 gene mutations in pheochromocytomas and paragangliomas. JAMA. 2010;304: 2611-2619.

18. Neumann HP, Sullivan M, Winter A, et al. Germline mutations of the TMEM127 gene in patients with paraganglioma of head and neck and extraadrenal abdominal sites. J Clin Endocrinol Metab. 2011;96:E1279-E1282.

19. Comino-Méndez I, Gracia-Aznarez FJ, Schiavi F, et al. Exome sequencing identifies MAX mutations as a cause of hereditary pheochromocytoma. Nat Genet. 2011;43:663-667. 
20. Lenders JW, Eisenhofer G, Mannelli M, Pacak K. Phaeochromocytoma. Lancet. 2005;366:665-675.

21. Ayala-Ramirez M, Feng L, Johnson MM, et al. Clinical risk factors for malignancy and overall survival in patients with pheochromocytomas and sympathetic paragangliomas: primary tumor size and primary tumor location as prognostic indicators. J Clin Endocrinol Metab. 2011;96:717-725.

22. Havekes B, King K, Lai EW, Romijn JA, Corssmit EP, Pacak K. New imaging approaches to phaeochromocytomas and paragangliomas. Clin Endocrinol (Oxf). 2010;72:137-145.

23. Taïeb D, Rubello D, Al-Nahhas A, Calzada M, Marzola MC, Hindie E. Modern PET imaging for paragangliomas: relation to genetic mutations. Eur J Surg Oncol. 2011;37:662-668.

24. Ilias I, Chen CC, Carrasquillo JA, et al. Comparison of $6-{ }^{18} \mathrm{~F}$-fluorodopamine PET with ${ }^{123}$ I-metaiodobenzylguanidine and ${ }^{111}$ In-pentetreotide scintigraphy in localization of nonmetastatic and metastatic pheochromocytoma. J Nucl Med. 2008;49:1613-1619.

25. Kaltsas GA, Mukherjee JJ, Grossman AB. The value of radiolabelled MIBG and octreotide in the diagnosis and management of neuroendocrine tumours. Ann Oncol. 2001;12(suppl 2):S47-S50.

26. van der Harst E, de Herder WW, Bruining HA, et al. ${ }^{123}$ I-metaiodobenzylguanidine and ${ }^{111}$ In-octreotide uptake in benign and malignant pheochromocytomas. J Clin Endocrinol Metab. 2001;86:685-693.

27. Tenenbaum F, Lumbroso J, Schlumberger M, et al. Comparison of radiolabeled octreotide and meta-iodobenzylguanidine (MIBG) scintigraphy in malignant pheochromocytoma. J Nucl Med. 1995;36:1-6.

28. Bustillo A, Telischi F, Weed D, et al. Octreotide scintigraphy in the head and neck. Laryngoscope. 2004;114:434-440.

29. Duet M, Sauvaget E, Petelle B, et al. Clinical impact of somatostatin receptor scintigraphy in the management of paragangliomas of the head and neck. $\mathrm{J} \mathrm{Nucl}$ Med. 2003;44:1767-1774.

30. Koopmans KP, Jager PL, Kema IP, Kerstens MN, Albers F, Dullaart RP. ${ }^{111}$ Inoctreotide is superior to ${ }^{123} \mathrm{I}$-metaiodobenzylguanidine for scintigraphic detection of head and neck paragangliomas. J Nucl Med. 2008;49:1232-1237.

31. Muros MA, Llamas-Elvira JM, Rodriguez A, et al. ${ }^{111}$ In-pentetreotide scintigraphy is superior to ${ }^{123} \mathrm{I}-\mathrm{MIBG}$ scintigraphy in the diagnosis and location of chemodectoma. Nucl Med Commun. 1998;19:735-742.

32. Schmidt M, Fischer E, Dietlein M, et al. Clinical value of somatostatin receptor imaging in patients with suspected head and neck paragangliomas. Eur J Nucl Med Mol Imaging. 2002;29:1571-1580.

33. Telischi FF, Bustillo A, Whiteman ML, et al. Octreotide scintigraphy for the detection of paragangliomas. Otolaryngol Head Neck Surg. 2000;122: $358-362$.

34. Charrier N, Deveze A, Fakhry N, et al. Comparison of ${ }^{111}$ In pentetreotideSPECT and ${ }^{18} \mathrm{~F}$ FDOPA-PET in the localization of extra-adrenal paragangliomas: the case for a patient-tailored use of nuclear imaging modalities. Clin Endocrinol (Oxf). 2011;74:21-29.

35. Shulkin BL, Koeppe RA, Francis IR, Deeb GM, Lloyd RV, Thompson NW. Pheochromocytomas that do not accumulate metaiodobenzylguanidine: localization with PET and administration of FDG. Radiology. 1993;186:711-715.

36. Shulkin BL, Thompson NW, Shapiro B, Francis IR, Sisson JC. Pheochromocytomas: imaging with $2-{ }^{18}$ fluorine-fluoro-2-deoxy-D-glucose PET. Radiology. 1999;212:35-41.

37. Garin E, Le Jeune F, Devillers A, et al. Predictive value of ${ }^{18} \mathrm{~F}$-FDG PET and somatostatin receptor scintigraphy in patients with metastatic endocrine tumors. J Nucl Med. 2009;50:858-864.

38. Robbins RJ, Wan Q, Grewal RK, et al. Real-time prognosis for metastatic thyroid carcinoma based on $2-{ }^{18} \mathrm{~F}$ fluoro-2-deoxy-D-glucose-positron emission tomography scanning. J Clin Endocrinol Metab. 2006;91:498-505.

39. Shulkin BL, Wieland DM, Schwaiger M, et al. PET scanning with hydroxyephedrine: an approach to the localization of pheochromocytoma. J Nucl Med. 1992;33: 1125-1131.

40. Pacak K, Eisenhofer G, Carrasquillo JA, Chen CC, Li ST, Goldstein DS. 6- ${ }^{18} \mathrm{~F}-$ fluorodopamine positron emission tomographic (PET) scanning for diagnostic localization of pheochromocytoma. Hypertension. 2001;38:6-8.

41. Saveanu A, Muresan M, De Micco C, et al. Expression of somatostatin receptors, dopamine D2 receptors, noradrenaline transporters and vesicular monoamine transporters in 52 pheochromocytomas and paragangliomas. Endocr Relat Cancer. 2011;18:287-300.

42. Hoegerle S, Nitzsche E, Altehoefer C, et al. Pheochromocytomas: detection with ${ }^{18}$ F DOPA whole body PET-initial results. Radiology. 2002;222: 507-512.

43. Timmers HJ, Hadi M, Carrasquillo JA, et al. The effects of carbidopa on uptake of $6-{ }^{18}$ F-fluoro-L-DOPA in PET of pheochromocytoma and extraadrenal abdominal paraganglioma. J Nucl Med. 2007;48:1599-1606.
44. Wild D, Macke HR, Waser B, et al. ${ }^{68} \mathrm{Ga}$-DOTANOC: a first compound for PET imaging with high affinity for somatostatin receptor subtypes 2 and 5. Eur J Nucl Med Mol Imaging. 2005;32:724.

45. Wild D, Schmitt JS, Ginj M, et al. DOTA-NOC, a high-affinity ligand of somatostatin receptor subtypes 2, 3 and 5 for labelling with various radiometals. Eur J Nucl Med Mol Imaging. 2003;30:1338-1347.

46. Reubi JC, Schar JC, Waser B, et al. Affinity profiles for human somatostatin receptor subtypes SST1-SST5 of somatostatin radiotracers selected for scintigraphic and radiotherapeutic use. Eur J Nucl Med. 2000;27:273-282.

47. Trampal C, Engler H, Juhlin C, Bergstrom M, Langstrom B. Pheochromocytomas: detection with ${ }^{11} \mathrm{C}$ hydroxyephedrine PET. Radiology. 2004;230: 423-428.

48. Franzius C, Hermann K, Weckesser M, et al. Whole-body PET/CT with ${ }^{11} \mathrm{C}$-meta-hydroxyephedrine in tumors of the sympathetic nervous system: feasibility study and comparison with ${ }^{123}$ I-MIBG SPECT/CT. J Nucl Med. 2006; 47:1635-1642.

49. Timmers HJ, Carrasquillo JA, Whatley M, et al. Usefulness of standardized uptake values for distinguishing adrenal glands with pheochromocytoma from normal adrenal glands by use of $6-{ }^{18}$ F-fluorodopamine PET. J Nucl Med. 2007;48:1940-1944.

50. Luster M, Karges W, Zeich K, et al. Clinical value of ${ }^{18}$ F-fluorodihydroxyphenylalanine positron emission tomography/computed tomography $\left({ }^{18} \mathrm{~F}-\mathrm{DOPA}\right.$ PET/CT) for detecting pheochromocytoma. Eur J Nucl Med Mol Imaging. 2010;37:484-493.

51. Bagheri B, Maurer AH, Cone L, Doss M, Adler L. Characterization of the normal adrenal gland with ${ }^{18}$ F-FDG PET/CT. J Nucl Med. 2004;45:1340-1343.

52. Leboulleux S, Deandreis D, Escourrou C, et al. Fluorodesoxyglucose uptake in the remaining adrenal glands during the follow-up of patients with adrenocortical carcinoma: do not consider it as malignancy. Eur J Endocrinol. 2011;164:89-94.

53. Timmers HJ, Chen CC, Carrasquillo JA, et al. Comparison of ${ }^{18} \mathrm{~F}$-fluoro-LDOPA, ${ }^{18} \mathrm{~F}$-fluoro-deoxyglucose, and ${ }^{18} \mathrm{~F}$-fluorodopamine PET and ${ }^{123} \mathrm{I}-\mathrm{MIBG}$ scintigraphy in the localization of pheochromocytoma and paraganglioma. J Clin Endocrinol Metab. 2009;94:4757-4767.

54. Fottner C, Helisch A, Anlauf M, et al. 6- ${ }^{18}$ F-fluoro-L-dihydroxyphenylalanine positron emission tomography is superior to ${ }^{123}$ I-metaiodobenzyl-guanidine scintigraphy in the detection of extraadrenal and hereditary pheochromocytomas and paragangliomas: correlation with vesicular monoamine transporter expression. J Clin Endocrinol Metab. 2010;95:2800-2810.

55. Mackenzie IS, Gurnell M, Balan KK, Simpson H, Chatterjee K, Brown MJ. The use of 18-fluoro-dihydroxyphenylalanine and 18-fluorodeoxyglucose positron emission tomography scanning in the assessment of metaiodobenzylguanidinenegative phaeochromocytoma. Eur J Endocrinol. 2007;157:533-537.

56. Fiebrich HB, Brouwers AH, Kerstens MN, et al. $6-{ }^{18}$ F-fluoro-L-dihydroxyphenylalanine positron emission tomography is superior to conventional imaging with ${ }^{123}$ I-metaiodobenzylguanidine scintigraphy, computer tomography, and magnetic resonance imaging in localizing tumors causing catecholamine excess. J Clin Endocrinol Metab. 2009;94:3922-3930.

57. Imani F, Agopian VG, Auerbach MS, et al. ${ }^{18} \mathrm{~F}$-FDOPA PET and PET/CT accurately localize pheochromocytomas. J Nucl Med. 2009;50:513-519.

58. Kauhanen S, Seppanen M, Ovaska J, et al. The clinical value of ${ }^{18} \mathrm{~F}$-fluorodihydroxyphenylalanine positron emission tomography in primary diagnosis, staging, and restaging of neuroendocrine tumors. Endocr Relat Cancer. 2009; $16: 255-265$.

59. Rufini V, Treglia G, Castaldi P, et al. Comparison of ${ }^{123}$ I-MIBG SPECT-CT and ${ }^{18}$ F-DOPA PET-CT in the evaluation of patients with known or suspected recurrent paraganglioma. Nucl Med Commun. 2011;32:575-582.

60. Timmers HJ, Eisenhofer G, Carrasquillo JA, et al. Use of $6-{ }^{18} \mathrm{~F}$-fluorodopamine positron emission tomography (PET) as first-line investigation for the diagnosis and localization of non-metastatic and metastatic phaeochromocytoma (PHEO). Clin Endocrinol (Oxf). 2009;71:11-17.

61. Mann GN, Link JM, Pham P, et al. ${ }^{11} \mathrm{C}$-metahydroxyephedrine and ${ }^{18} \mathrm{~F}$-fluorodeoxyglucose positron emission tomography improve clinical decision making in suspected pheochromocytoma. Ann Surg Oncol. 2006;13:187-197.

62. Hadi M, Chen CC, Whatley M, Pacak K, Carrasquillo JA. Brown fat imaging with ${ }^{18} \mathrm{~F}$-6-fluorodopamine PET/CT, ${ }^{18} \mathrm{~F}$-FDG PET/CT, and ${ }^{123} \mathrm{I}-\mathrm{MIBG}$ SPECT: a study of patients being evaluated for pheochromocytoma. J Nucl Med. 2007;48:1077-1083.

63. Kaji P, Carrasquillo JA, Linehan WM, et al. The role of $6-{ }^{18} \mathrm{~F}$-fluorodopamine positron emission tomography in the localization of adrenal pheochromocytoma associated with von Hippel-Lindau syndrome. Eur J Endocrinol. 2007;156: 483-487.

64. Taïeb D, Sebag F, Barlier A, et al. ${ }^{18}$ F-FDG avidity of pheochromocytomas and paragangliomas: a new molecular imaging signature? J Nucl Med. 2009; 50:711-717. 
65. Naji M, Zhao C, Welsh SJ, et al. ${ }^{68}$ Ga-DOTA-TATE PET vs. ${ }^{123}$ I-MIBG in identifying malignant neural crest tumours. Mol Imaging Biol. 2011;13:769-775.

66. Win Z, Rahman L, Murrell J, Todd J, Al-Nahhas A. The possible role of ${ }^{68} \mathrm{Ga}-$ DOTATATE PET in malignant abdominal paraganglioma. Eur J Nucl Med Mol Imaging. 2006;33:506.

67. Win Z, Al-Nahhas A, Towey D, et al. ${ }^{68} \mathrm{Ga}$-DOTATATE PET in neuroectodermal tumours: first experience. Nucl Med Commun. 2007;28:359-363.

68. Fanti S, Ambrosini V, Tomassetti P, et al. Evaluation of unusual neuroendocrine tumours by means of ${ }^{68} \mathrm{Ga}$-DOTA-NOC PET. Biomed Pharmacother. 2008;62: $667-671$.

69. Grassi I, Nanni C, Vicennati V, et al. ${ }^{123}$ I-MIBG scintigraphy and ${ }^{68}$ Ga-DOTANOC PET/CT negative but ${ }^{18} \mathrm{~F}$-DOPA PET/CT positive pheochromocytoma: a case report. Clin Nucl Med. 2011;36:124-126.

70. Naswa N, Sharma P, Nazar AH, et al. Prospective evaluation of ${ }^{68}$ Ga-DOTANOC PET-CT in phaeochromocytoma and paraganglioma: preliminary results from a single centre study. Eur Radiol. October 5, 2011 [Epub ahead of print].

71. Rahbar K, Kies P, Stegger L, Juergens KU, Weckesser M. Discrepancy between glucose metabolism and sympathetic nerve terminals in a patient with metastatic paraganglioma. Eur J Nucl Med Mol Imaging. 2008;35:687.

72. Ilias I, Yu J, Carrasquillo JA, et al. Superiority of $6-{ }^{18} \mathrm{~F}$-fluorodopamine positron emission tomography versus ${ }^{131}$ I-metaiodobenzylguanidine scintigraphy in the localization of metastatic pheochromocytoma. J Clin Endocrinol Metab. 2003; 88:4083-4087.

73. Taïeb D, Tessonnier L, Sebag F, et al. The role of ${ }^{18}$ F-FDOPA and ${ }^{18}$ F-FDG-PET in the management of malignant and multifocal phaeochromocytomas. Clin Endocrinol (Oxf). 2008;69:580-586.

74. Kroiss A, Putzer D, Uprimny C, et al. Functional imaging in phaeochromocytoma and neuroblastoma with ${ }^{68} \mathrm{Ga}$-DOTA-Tyr 3-octreotide positron emission tomography and ${ }^{123}$ I-metaiodobenzylguanidine. Eur J Nucl Med Mol Imaging. 2011;38:865-873.

75. Zelinka T, Timmers HJ, Kozupa A, et al. Role of positron emission tomography and bone scintigraphy in the evaluation of bone involvement in metastatic pheochromocytoma and paraganglioma: specific implications for succinate dehydrogenase enzyme subunit B gene mutations. Endocr Relat Cancer. 2008;15:311-323.

76. Timmers HJ, Kozupa A, Chen CC, et al. Superiority of fluorodeoxyglucose positron emission tomography to other functional imaging techniques in the evaluation of metastatic SDHB-associated pheochromocytoma and paraganglioma. J Clin Oncol. 2007;25:2262-2269.

77. Ambrosini V, Nanni C, Zompatori M, et al. ${ }^{68}$ Ga-DOTA-NOC PET/CT in comparison with CT for the detection of bone metastasis in patients with neuroendocrine tumours. Eur J Nucl Med Mol Imaging. 2010;37:722-727.

78. Poeppel TD, Yuece A, Boy C, et al. Novel SDHD gene mutation (H102R) in a patient with metastatic cervical paraganglioma effectively treated by peptide receptor radionuclide therapy. J Clin Oncol. 2011;29:e812-e815.
79. Hoegerle S, Ghanem N, Altehoefer C, et al. ${ }^{18}$ F-DOPA positron emission tomography for the detection of glomus tumours. Eur J Nucl Med Mol Imaging. 2003;30:689-694.

80. King KS, Chen CC, Alexopoulos DK, et al. Functional imaging of SDHx-related head and neck paragangliomas: comparison of ${ }^{18} \mathrm{~F}$-fluorodihydroxyphenylalanine, ${ }^{18}$ F-fluorodopamine, ${ }^{18} \mathrm{~F}$-fluoro-2-deoxy-D-glucose PET, ${ }^{123}$ I-metaiodobenzylguanidine scintigraphy, and ${ }^{111}$ In-pentetreotide scintigraphy. J Clin Endocrinol Metab. 2011;96:2779-2785.

81. King KS, Whatley MA, Alexopoulos DK, et al. The use of functional imaging in a patient with head and neck paragangliomas. J Clin Endocrinol Metab. 2010; 95:481-482.

82. Kroemer G, Pouyssegur J. Tumor cell metabolism: cancer's Achilles' heel. Cancer Cell. 2008;13:472-482.

83. Jones RG, Thompson CB. Tumor suppressors and cell metabolism: a recipe for cancer growth. Genes Dev. 2009;23:537-548.

84. Vander Heiden MG, Cantley LC, Thompson CB. Understanding the Warburg effect: the metabolic requirements of cell proliferation. Science. 2009;324:10291033.

85. Pollard PJ, Briere JJ, Alam NA, et al. Accumulation of Krebs cycle intermediates and over-expression of HIF1alpha in tumours which result from germline $\mathrm{FH}$ and SDH mutations. Hum Mol Genet. 2005;14:2231-2239.

86. Selak MA, Armour SM, MacKenzie ED, et al. Succinate links TCA cycle dysfunction to oncogenesis by inhibiting HIF-alpha prolyl hydroxylase. Cancer Cell. 2005;7:77-85.

87. MacKenzie ED, Selak MA, Tennant DA, et al. Cell-permeating alpha-ketoglutarate derivatives alleviate pseudohypoxia in succinate dehydrogenase-deficient cells. Mol Cell Biol. 2007;27:3282-3289.

88. Bardella C, Pollard PJ, Tomlinson I. SDH mutations in cancer. Biochim Biophys Acta. 2011;1807:1432-1443.

89. Pollard PJ, El-Bahrawy M, Poulsom R, et al. Expression of HIF-1alpha, HIF-2alpha (EPAS1), and their target genes in paraganglioma and pheochromocytoma with VHL and SDH mutations. J Clin Endocrinol Metab. 2006;91:45934598.

90. Favier J, Briere JJ, Burnichon N, et al. The Warburg effect is genetically determined in inherited pheochromocytomas. PLOS ONE. 2009;4:e7094.

91. López-Jiménez E, Gomez-Lopez G, Leandro-Garcia LJ, et al. Research resource: transcriptional profiling reveals different pseudohypoxic signatures in SDHB and VHL-related pheochromocytomas. Mol Endocrinol. 2010;24:2382-2391.

92. Burnichon N, Vescovo L, Amar L, et al. Integrative genomic analysis reveals somatic mutations in pheochromocytoma and paraganglioma. Hum Mol Genet. 2011;20:3974-3985.

93. Span PN, Rao JU, Oude Ophuis B, et al. Overexpression of the natural antisense hypoxia-inducible factor-1alpha transcript is associated with malignant phaeochromocytoma/paraganglioma. Endocr Relat Cancer. 2011;18:323-331. 